\title{
Menopoz ile İlişkili Semptomlara Yönelik Kanıta Dayalı Uygulamaların İncelenmesi
}

\author{
Ebru BEKMEZCi'1 (i) Kamile ALTUNTUĞ2 (ic
}

1 Selçuk Üniversitesi, Hemşirelik Fakültesi, Doğum ve Kadın Hastalıkları Hemşireliği Anabilim Dalı, Konya, Türkiye ebrubekmezci42@gmail.com (Sorumlu Yazar/Corresponding Author)

2 Necmettin Erbakan Üniversitesi, Hemşirelik Fakültesi, Doğum ve Kadın Hastalıkları Hemşireliği Anabilim

Dalı, Konya, Türkiye, kaltuntug@yahoo.com

\begin{tabular}{|c|c|}
\hline Makale Bilgileri & ÖZ \\
\hline $\begin{array}{l}\text { Makale Geçmişi } \\
\text { Geliş: } 12.06 .2020 \\
\text { Kabul: } 19.07 .2020 \\
\text { Yayın: } 25.12 .2020 \\
\text { Anahtar Kelimeler: } \\
\text { Menopoz, } \\
\text { Postmenopoz, } \\
\text { Premenopoz }\end{array}$ & $\begin{array}{l}\text { Menopoz, } 12 \text { aylık amenorenin ardından adet kanamasının kalıcı olarak kesilmesi durumudur. } \\
\text { Kadınların doğal üreme döngüsünün sonunu işaret eden önemli bir yaşam evresidir. Kadınlar } \\
\text { arasında değişmekle birlikte genellikle ortalama görülme yaşıın } 51 \text { olduğu belirtilmektedir. } \\
\text { Menopoz döneminde kadınlar tarafından birçok semptom bildirilmekte ve ortaya çıan bu } \\
\text { semptomlar kadınlarda fizyolojik, mental, sosyal ve cinsel yönden birçok değişime neden } \\
\text { olmaktadır. Kadınların sosyodemografik, obstetrik ve evlilik özelliklerinin de menopoz } \\
\text { semptomlarının ortaya çıkmasında etken olduğu belirtilmektedir. En çok görülen semptomlar } \\
\text { arasında vazomotor semptomlar, genitoüriner sendrom, uyku bozuklukları, psikolojik } \\
\text { değişiklikler ve osteoporoz gibi belirtiler yer almaktadır. Bireyin yaşam kalitesini ve } \\
\text { işlevselliğini etkileyen bu semptomlara yönelik çeşitli tedavi seçenekleri mevcuttur. Tedaviye } \\
\text { karar vermeden önce kadınlara tedaviler hakkında bilgi verilmeli ve en uygun yönteme birlikte } \\
\text { karar verilmelidir. Hormon tedavisi, biyolojik hormon tedavisi, bilişsel davranışçı terapi, } \\
\text { davranış değişiklikleri, hipnoz, egzersiz, gevşeme teknikleri bu tedavilerden bazılarıdır. } \\
\text { Bunların yanında bazı bitkilerinde menopoz semptomları üzerinde yararlı olabileceği } \\
\text { belirtilmektedir. Menopozal semptomların önlenmesi ve tedavisinin kanita dayalı } \\
\text { uygulamaların kullanılması ile sağlanabileceği düşünülmektedir. Bu nedenle kanıta dayalı } \\
\text { uygulamaların sağlı profesyonelleri tarafindan kullanılması bakım kalitesinin arttırılmasina ve } \\
\text { etkin bakım verilmesinde son derece önemlidir. Hasta ile en çok zaman geçiren meslek grubu } \\
\text { olan hemşireler başta olmak üzere, tüm sağlı profesyonellerinin kanıta dayalı uygulamalar } \\
\text { yapması, araştırması ve uygulamalara aktarabilmesi büyük önem taşımaktadır. }\end{array}$ \\
\hline
\end{tabular}

\section{Examination of Evidence Based Practices for Symptoms Associated with Menopause}

\begin{tabular}{|c|c|}
\hline Article Info & ABSTRACT \\
\hline $\begin{array}{l}\text { Article History } \\
\text { Received: } 12.06 .2020 \\
\text { Accepted: } 19.07 .2020 \\
\text { Published: } 25.12 .2020 \\
\text { Keywords: } \\
\text { Menopause, } \\
\text { Postmenopausal, } \\
\text { Premenopause }\end{array}$ & $\begin{array}{l}\text { Menopause is a permanent cessation of menstrual bleeding after } 12 \text { months of amenorrhea. It is an } \\
\text { important life cycle that marks the end of the women's natural reproductive cycle. Although it varies } \\
\text { among women, it is generally stated that the average age of occurrence is } 51 \text {. Many symptoms are } \\
\text { reported by women during menopause, and these symptoms cause physiological, mental, social and } \\
\text { sexual changes in women. It is stated that sociodemographic, obstetric and marital features of women } \\
\text { are effective in the emergence of menopausal symptoms. The most common symptoms include } \\
\text { vasomotor symptoms, genitourinary syndrome, sleep disorders, psychological changes, and } \\
\text { osteoporosis. There are various treatment options for these symptoms that affect the quality of life and } \\
\text { functionality of the individual. Before deciding on the treatment, women should be informed about the } \\
\text { treatments and the most appropriate method should be decided together. Hormone therapy, biological } \\
\text { hormone therapy, cognitive behavioral therapy, behavior changes, hypnosis, exercise, relaxation } \\
\text { techniques are some of these treatments. In addition, it is stated that some plants may be beneficial on } \\
\text { menopausal symptoms. It is thought that the prevention and treatment of menopausal symptoms can be } \\
\text { achieved by using evidence-based practices. Therefore, the use of evidence-based practices by } \\
\text { healthcare professionals is extremely important in improving the quality of care and providing effective } \\
\text { care. It is of great importance that all healthcare professionals, especially nurses, who spend the most } \\
\text { time with the patient, are able to carry out evidence-based practices, research and transfer them to } \\
\text { practices. }\end{array}$ \\
\hline
\end{tabular}

Atıf/Citation: Bekmezci, E.\& Altuntuğ, K. (2020). Menopoz ile ilişkili semptomlara yönelik kanıta dayalı uygulamaların incelenmesi, Genel Sağllk Bilimleri Dergisi, 2(3), 167-174. 


\section{GÍRIŞ}

Eski Yunanca'da men (ay) ve pausis (sonlanma) sözcüklerinden köken alan menopoz (Kilci ve Ertem, 2019), over aktivitesinin durması ile 12 aylık amenorenin ardından teşhis edilen, patolojik veya hormonal nedenlerle açılanamayan adet kanamasının kalıcı olarak kesilmesi durumu olarak tanımlanmaktadır (Karanth, Chuni, ve Nair, 2019; Roberts ve Hickey, 2016). Kadınların doğal üreme döngüsünün sonunu işaret eden önemli bir yaşam evresi olup (Daley, Stokes-Lampard, Thomas, ve MacArthur, 2014), ortalama görülme yaşının 51 olduğu belirtilmektedir (Kagan, Kellogg-Spadt, ve Parish, 2019). Temel mekanizma östrojen seviyesinin azalması ve folikül uyarıcı hormon (FSH) seviyesinin artmasına bağlı olmaktadır (Casper, 2019; Santoro, Epperson, ve Mathews, 2015). Menopozun 2-6 y1l öncesi premenopozal dönem, 6-8 y1l sonrası postmenopozal dönem olarak adlandırılmaktadır (Bozkurt \& Sevil, 2016). Perimenopozal dönem ise adet düzensizliği ile başlayıp son adeti takip eden 12 aylık erken postmenopozal süreyi kapsamaktadır (Monteleone, Mascagni, Giannini, Genazzani, ve Simoncini, 2018). Perimenopozal dönem, menopozal geçiş dönemi olarak da adlandırılmaktadır (NICE, 2015).

Menopoz döneminde kadınlar tarafından birçok semptom bildirilmekte olup (Santoro et al., 2015), ortaya çıkan bu semptomlar kadınlarda fizyolojik, mental, sosyal ve cinsel yönden birçok değişime neden olmaktadır (Gönenç \& Koç, 2019). En ağır semptomlar premenopoz sırasında adet döngüsünün foliküler ve luteal fazlarında meydana gelen seks hormonları seviyelerindeki belirgin dalgalanmalar nedeniyle görülmektedir. Postmenopozda ise östrojen yokluğuna bağlı olarak vazomotor semptomlar, ürogenital atrofi, cildin yaşlanması, uyku bozuklukları, psikolojik değişiklikler ve osteoporoz gibi belirtiler ortaya çıkabilmektedir (Lethaby, Ayeleke, \& Roberts, 2016; Monteleone et al., 2018). Kadınların sosyodemografik ve evlilik özelliklerininde menopoz semptomlarının ortaya çıkmasında etken olduğu belirtilmektedir (Özcan \& Oskay, 2013). Menopozun bireyin yaşam kalitesini ve işlevselliğini etkileyen bu semptomlarına yönelik çeşitli tedavi seçenekleri mevcuttur (Roberts \& Hickey, 2016). Sağlık profesyonellerinin bireylere en etkili ve yararlı tedaviyi sağlamasında kanıta dayalı uygulamaların önemi artmaktadır. Bu nedenle derleme, menapozda semptom yönetiminde uygulanan tedavi yöntemlerini klinik kanıtlar çerçevesinde incelemek amacıyla yapılmıştır. Bu derlemede menopozal semptomlar; vazomotor semptomlar, uyku bozuklukları, genitoüriner sendrom, osteoporoz ve psikolojik sorunlar başlıkları altında incelenmiştir.

\section{Vazomotor Semptomlar}

Vazomotor semptomlar, vücudun üst kısmında ani bir 1sı artış1, kızarıklık, kalp çarpıntısı, titreme ve terleme ile karakterize menopozal semptomlardır (Ward \& Deneris, 2018). Menopoz döneminde çoğu kadını etkilemekle birlikte kadınlar arasında da şiddet, sıklık ve süre açısından farklılık gösterebilmektedir (Santoro et al., 2015). Sicak basmasının en sık görülen vazomotor semptom olduğu belirtilmektedir (Dodin et al., 2013). Genellikle yüz, boyun ve gögüste ani bir 1s1 artış hissi olarak ortaya çıkmakta ve buna genellikle ciltte kızarma, terleme eşlik etmektedir. Gece boyunca meydana gelen sıcak basması genellikle gece terlemesi olarak adlandırılır. Bu durum uyku düzenini ve günlük aktiviteleri değiştirebilir, bu da bireyin yaşam kalitesinin düşmesine neden olabilmektedir (Daley et al., 2014).

Vazomotor semptomlarda tedaviyi yönlendiren temel düşünce rahatsız edici semptomların ne olduğunun belirlenmesidir. Tedaviye karar vermeden önce kadınlara davranışsal ve farmakolojik tedaviler hakkında bilgi verilmeli en uygun yönteme karar verilmelidir (Roberts \& Hickey, 2016). "Amerikan Kadın Doğum Uzmanları ve Jinekologlar Koleji” (ACOG) ve "Kuzey Amerika Menopoz Derneği” (NAMS) sadece östrojen içeren veya progesteron ile birlikte östrojen içeren hormon tedavilerinin menopoza bağlı vazomotor semptomları azaltmada en etkili tedavi yöntemi olduğunu belirtmektedirler. Nedeni belirlenmeyen vajinal kanama, aktif karaciğer hastalığı, meme kanseri riski, koroner kalp hastalığı, inme, tromboembolik hastalık öyküsü ve kalıtsal risk taşıyan hastalarda hormon tedavisinden kaçınılması gerektiğide önemle vurgulanmaktadır (Faubion et al., 2018; Kagan et al., 2019; Roberts \& Hickey, 2016). Hormon tedavisinin kontrendike olduğu durumlarda ise düşük doz paroksetin veya diğer seçici serotonin 
geri alım inhibitörleri önerilmektedir (ACOG, 2014; NAMS, 2010). Biyolojik hormon tedavisinin sicak basması ve gece terlemesi gibi menopoz semptomlarının tedavisinde etkili olduğu fakat çalışmaların düşük ila orta düzey kanıtlara dayandığ tibolunun (Kazandı \& Akman, 2007), postmenopozal kadınlarda kemik, vajina, cinsel şikayetler ve vazomotor semptomları azalttığı ancak hormon tedavisinden daha az etkili olduğu bulunmuştur (Formoso et al., 2016). Davranış değişikliği uygulanabilir olduğunda vazomotor semptomlar için ilk basamak tedavi seçeneği olarak önerilmektedir (Tong, 2013). Oda 1sısını serin tutmanın ve katmanlı giysilerle giyinmenin hafif semptomları olan kadınlar için rahatlama sağlayabileceği belirtilmektedir (Nelson et al., 2006). Klinik kanıtlar yetersiz olsada yapılan çalışmalarda kilo kaybının, bilişsel davranışçı terapinin, E vitaminin ve hipnozun plasebo gruplarına göre semptomlar üzerinde daha etkili oldukları belirtilmektedir (Santen, Loprinzi, \& Casper, 2019; Ziaei, Kazemnejad, \& Zareai, 2007). Yapılan çalışmalarda sıcak basması için, düzenli yapılan egzersizin, gevşeme tekniklerinin ve yavaş tempolu solunum tekniklerinin etkili olabileceği fakat konuyla ilgili kanıtların yetersiz olduğu vurgulanmaktadır (Daley et al., 2014; Huang, Phillips, Schembri, Vittinghoff, \& Grady, 2015; Suprawita Saensak, Vutyavanich, Somboonporn, \& Srisurapanont, 2013; S. Saensak, Vutyavanich, Somboonporn, \& Srisurapanont, 2014). Akupunktur, refleksoloji ve manyetik terapi gibi tamamlayıcı tedavilerin vazomotor semptomlar üzerindeki etkisi hakkında kesin bir bilgi bulunmamaktadır (Dodin et al., 2013; Tong, 2013). Yapılan araştırmalarda bazı bitkilerin menopozal semptomları azaltabileceği vurgulanmaktadır. Örneğin kara yılan otunun etki mekanizması tam olarak açıklığa kavuşmamış olmasına rağmen, vazomotor semptomları hafifletebileceği belirtilmektedir (NICE, 2015). Kadın ginsengi olarak bilinen Çin Melekotu'nun, soyanın (Gün \& Demirci, 2015) ve lavantanın sıcak basması ve diğer menopoz semptomlarının kontrolünde yararlı olabileceği yapılan çalışmalarda belirtilmektedir (Salehi-Pourmehr, Ostadrahimi, Ebrahimpour-Mirzarezaei, \& Farshbaf-Khalili, 2020).

\section{Uyku Bozuklukları}

Menopoz dönemindeki kadınların yaklaşık \%40-60'ında uyku ile ilgili sorunlar görülmekte olup, bunlardan en s1k olarak gece uyanmalarının görüldüğü belirtilmektedir. Menopozun uyku bozukluğuna nasıl neden olduğu ile ilgili mekanizma tam olarak açıklanamasada (Cintron et al., 2017), sıklıkla vazomotor semptomlardan, değişen hormon seviyelerinden, yaşam tarzı faktörlerinden ve var olan diğer tıbbi durumalardan kaynaklanabileceği düşünülmektedir (Ameratunga, Goldin, \& Hickey, 2012).

Uyku kalitesi sağlığın ve yaşam kalitesinin önemli bir belirleyicisi olması nedeniyle etkili bir tedavi yaklaşımı gerektirmektedir. Ortaya çıkan uyku bozuklukları tedavi edilmediği zaman kardiyovasküler hastalık, diyabet, obezite ve nörodavranışsal disfonksiyon gelişmesi için bir risk faktörü olabilmektedir (Cintron et al., 2017). Tedavide yaklaşım klinik bulgulara göre yapılmalı ve uyku bozukluğunu etkileyebilecek ilişkili faktörlerin ele alınması gerekmektedir (Santoro et al., 2015). Örneğin sıcak basmas1 ve gece terlemesi gibi vazomotor semptomların neden olduğu uyku bozukluğu için kullanılan tedavi yöntemlerinin dolaylı olarak uyku kalitesinide arttırdı̆̆ belirtilmektedir (Timur \& Hotun Şahin, 2010). Hormon tedavisinin uyku üzerindeki etkisine bakıldığında, sadece östrojen içeren ve hem östrojen hem progesteron içeren hormon tedavilerinin yararlı etkileri olabileceği vurgulanmaktadır (Ameratunga et al., 2012). Bunun yanında bilişsel davranışçı terapininde farmakolojik tedavilere göre daha az yan etkisinin bulunması ve spesifik problemlerde etkili olması nedeniyle uyku bozuklukları için yararlı olabileceği belirtilmektedir (Santen et al., 2019; Soares \& Murray, 2006).

\section{Genitoüriner Sendrom}

Genitoüriner sendrom, menopoz döneminde cinsiyet hormonlarında meydana gelen azalma sonucu, labia major/mimör, klitoris, vestibul, vajina, üretra ve mesanede meydana gelen değişiklikleri tanımlamaktadır (Kagan et al., 2019; Karakoç, Özerdoğan, \& Uçtu, 2017). Menopoz dönemindeki kadınların yaklaşı \% \%0'sini etkileyen kronik ve ilerleyici bir durum olarak belirtilmektedir (Kagan et al., 2019). Genitoüriner sendrom belirtileri menopoz döneminde azalan östrojen miktarıyla ilişkili olarak vulvovajinal atrofi, vajinal kuruluk ve ürogenital değişiklikler gibi semptomlarla karakterizedir. Bunlar 
cinsel ilişki sırasında ağrı, libido kaybı, idrar yolu enfeksiyonu ve idrar kaçırma durumlarının ortaya çıkmasına neden olabilmektedir (Ward \& Deneris, 2018). Tanı genellikle subjektif ölçütlerle değerlendirilsede, vajinal $\mathrm{pH}$ ölçümü ve vajinal smearden alınan vajinal maturasyon indeksi de objektif kanıt oluşturmada yarar sağlamaktadır (Karakoç et al., 2017).

Tüm bunlar kadınların yaşam kalitesinin olumsuz etkilemekte (Kagan et al., 2019) ve etkili tedavi yollarının belirlenmesini gerekli kılmaktadır. NAMS, genitoüriner sendromların birinci basamak yönetiminde hormonal olmayan vajinal yağlayıcı/nemlendiricileri önermektedir (NAMS, 2013). Özellikle cinsel ilişki sırasında vajinal yağlayıcı/nemlendirici kullanılmasının yaşanan ağrının azaltılmasında yararlı olabileceği belirtilmektedir. Yapılan çalışmada genitoüriner sendroma yönelik vajinal östrojen ile hormonal olmayan yağlayıcı/nemlendirici arasında etkinlik açısında çok az fark bulunmuştur (Mitchell et al., 2018). Hormonal olmayan tedavilerden yanıt alınamadığı zaman düşük ila orta dereceli vajinal atrofi için herhangi bir kontrendikasyonu olmayan kadınlarda vajinal östrojen kullanımının en etkili tedavi olduğu belirtilmektedir (Bachmann \& J Santen, 2020; Biehl, Plotsker, \& Mirkin, 2019; NAMS, 2013). Hormon tedavisinin vajinal atrofi ve disparonin hafifletilmesinde etkili olabileceği fakat azalmış libido kaybı gibi diğer cinsel sorunlarda tek tedavi çeşidi olarak önerilemeyeceği belirtilmektedir (NAMS, 2010).

İdrar kaçırma sorunu olan kadınlar için yapılan sistematik derlemede orta düzeyde kanıt ile pelvik taban egzersizlerinin ve mesena eğitiminin kadınlarda idrar kaçırma sorununu çözdüğünü göstermektedir (Shamliyan, Kane, Wyman, \& Wilt, 2008). Egzersizin, en az 15-20 hafta boyunca haftada 3-4 kez olmak üzere, her biri 6-8 saniye süren üç setlerden oluşması gerektiği belirtilmektedir (Tong, 2013). Bunların yanında herhangi bir kontrendikasyonu olmayan kadınlarda lokal östrojen tedavisinin idrar inkontinansında etkili olduğu ifade edilmektedir (Cody, Jacobs, Richardson, Moehrer, \& Hextall, 2012; Lethaby et al., 2016). Ağrı nedeniyle cinsel ilişkiden kaçınan, östrojen tedavisine kontrendikasyonu olan ve nemlendirici/yağlayıcı kullanımında başarısız olan kadınlar için vajinal dilatörler önerilmektedir (Bachmann \& J Santen, 2020).

\section{Osteoporoz}

Osteoporoz, kemik kütlesi ve dokusunda meydana gelen bozulmalar sonucu kemik kırılganlığının artması ile karakterize sistemik bir hastalıktır (Levin, Jiang, \& Kagan, 2018; Sindel \& Gula, 2015). Menopoz döneminde görülen önemli sağlık sorunları arasında yer almakta olup, önemli morbidite ve mortalite sebebi olarak gösterilmektedir (Radominski et al., 2017). Östrojen hormon seviyesinde meydana gelen azalma temel neden olarak gösterilmektedir (Ward \& Deneris, 2018). Osteoporoz yönetimi farmakolojik ve farmakolojik olmayan tedavi yöntemlerini içermektedir. Farmakolojik tedaviden yararlanma olasılığı en yüksek kadınlar kırık riski yüksek olan kadınlar olarak belirtilmektedir. Kırık öyküsü olan veya kemik mineral yoğunluğu ölçüm değeri $\mathrm{T}$ skoru $\leq-2.5$ olan postmenopozal kadınlar için farmakolojik tedavi önerilmektedir (Rosen \& Drezner, 2020). Osteoporotik kırıklarda kullanılan ilaçlar arasında hormon replasman tedavisi, bifosfonatlar, kalsitonin, seçici östrojen reseptör modülatörleri ve D vitamini türevi yer almaktadır (Sangkomkamhang, Sangkomkamhang, \& Ngamjarus, 2010). Premenopozal kadınlarda devam eden kemik kaybı ya da düşük travmalı kırıklar olmadıkça farmakolojik tedavinin düşünülmemesi gerektiği, postmenopozal kadınlarda ise bisfosfonatların ilk basamak tedavi olarak kullanılması yüksek kanıt düzeyi ile önerilmektedir (TEMD, 2019). Bisfosfonat grupları, diğer ilaçlara göre daha maliyetli olup gastrointestinal yan etkiler gösterebilmektedir (Sangkomkamhang et al., 2010). "Ulusal Sağlık ve Bakım Mükemmelliği Enstitüsü” (NICE), hormon replesman tedavisinin kemiklerin kırılma riskini azalttığını ancak meme kanseri riskinde artış gibi uzun süreli kullanımdan sonra nadir görülen yan etkileri olabileceğini belirtmektedir (NICE, 2015). Yeterli miktarda A, D, K vitamini (Özcan \& Oskay, 2013), protein, magnezyum ve fitoöstrojen alımının kemik gücünü arttırdığ1 ifade edilmektedir. Hızlı yürüyüş, koşu ve kuvvet antremanının kas gücünün iyileştirmede etkili olduğu vurgulanmaktadır (Tong, 2013). Egzersizin postmenopozal kadınlarda omurga ve kalçada kemik yoğunluğunu artırmada etkili olduğu ancak kırıkları önlemede etkisinin olmadığı belirtilmektedir (Sangkomkamhang et al., 2010). 


\section{Psikolojik Sorunlar}

Premenopozal ve postmenopozal dönemlerde östrojen seviyesinde meydana gelen dalgalanmalara bağlı olarak merkezi sinir sistemi etkilenmekte ve bir takım ruhsal değişiklikler ortaya çıkabilmektedir (Özcan \& Oskay, 2013). Menopozla birlikte kadınların psikolojik sıkıntıların 2-4 kat arttığı belirtilmektedir (Santoro et al., 2015). En sık olarak bireyin kendini üzgün, sinirli, gergin, huzursuz hissetmesi görülürken aynı zamanda konsantrasyonu zorlaştırarak unutkanlığında ortaya çıkmasına neden olabilmektedir (Özcan \& Oskay, 2013). Tüm bu etkilerin yanında menopoz döneminin bereberinde getirdiği semptomlarla birlikte kadınların kendini yaşlı hissederek benlik saygısının azalmasınada neden olduğu belirtilmektedir (Kagan et al., 2019). Kadını etkileyen çevresel stres faktörlerinide göz önüne alarak, sıkıntıya neden olan durumun belirlenmesi ve kadına gereken desteğin sağlanması tedavide temel yaklaşım noktasını oluşturmaktadır (Santoro et al., 2015). Menopoz ile ilişkili psikolojik belirtiler için bireylere psikoterapinin yarar sağladığ belirtilmektedir (Nelson et al., 2006). Bunun yanında artan psikolojik sorunlara yönelik yapılan çalışamalarda yoga önerilmektedir. Yoganın rahatsız edici psikolojik semptomlar için yararlı bir tedavi olabileceği belirtilmektedir (Cramer, Lauche, Langhorst, \& Dobos, 2012; Shepherd-Banigan et al., 2017). Yapılan çalışmalar incelendiğinde sarı kantaronun depresyon tedavisinin yanı sıra menopozal belirtilerin tedavisinde yarar sağlayabileceği belirtilmektedir (Gün \& Demirci, 2015). Perimenopozal kadınlarda sarı kantaron ile yapılan randomize kontrollü bir çalışmada menopoza özgü yaşam kalitesinde anlamlı düzeyde iyileşme olduğu bulunmuştur (Al-Akoum et al., 2009).

\section{SONUÇ VE ÖNERILER}

Kadınların önemli bir yaşam evresini temsil eden menopozal dönemde, ortaya çıkan semptomların yönetimi büyük önem taşımaktadır. Menopozal semptomların önlenmesi ve tedavisinin kanıta dayalı uygulamaların kullanılması ile sağlanabileceği düşünülmektedir. Bu nedenle kanıta dayalı uygulamaların sağlık profesyonelleri tarafından kullanılması bakım kalitesinin arttırılmasına ve etkin bakım verilmesinde son derece önemlidir. Hasta ile en çok zaman geçiren meslek grubu olan hemşireler başta olmak üzere, tüm sağlık profesyonellerinin kanıta dayalı uygulamalar yapması, araştırması ve uygulamalara aktarabilmesi büyük önem taşımaktadır.

\section{Finansal destek}

Finansal destek alınmamıştır.

\section{Çıkar çatışması}

Çıkar çatışması yoktur.

\section{Yazarlık Katkıları:}

Tasarım/Design: E.B., K.A.; Literatür Tarama/Literature Search: E.B.; Yazma/Writing: E.B., K.A.

\section{KAYNAKÇA}

ACOG. (2014). ACOG Practice bulletin no. 141: management of menopausal symptoms. Obstetrics and Gynecology, 123(1), 202-216. doi:10.1097/01.AOG.0000441353.20693.78.

Al-Akoum, M., Maunsell, E., Verreault, R., Provencher, L., Otis, H., \& Dodin, S. (2009). Effects of hypericum perforatum (St. John's wort) on hot flashes and quality of life in perimenopausal women: a randomized pilot trial. Menopause (New York, N.Y.), 16(2), 307-314. doi:10.1097/gme.0b013e31818572a0.

Ameratunga, D., Goldin, J., \& Hickey, M. (2012). Sleep disturbance in menopause. Internal Medicine Journal, 42(7), $742-$ 747. doi:10.1111/j.1445-5994.2012.02723.x.

Bachmann, G., \& J Santen, M. (2020). Treatment of genitourinary syndrome of menopause (vulvovaginal atrophy). UptoDate, Erişim Adresi: https://www.uptodate.com/contents/treatment-of-genitourinary-syndrome-of-menopausevulvovaginal-atrophy.

Biehl, C., Plotsker, O., \& Mirkin, S. (2019). A systematic review of the efficacy and safety of vaginal estrogen products for the treatment of genitourinary syndrome of menopause. Menopause (New York, N.Y.), 26(4), 431-453. doi:10.1097/gme.0000000000001221.

Bozkurt, Ö. D., \& Sevil, Ü. (2016). Menopoz ve cinsel yaşam. Celal Bayar Üniversitesi Sağllk Bilimleri Enstitüsü Dergisi, 3(4), 497-503. 
Casper, F. R. (2019). Clinical manifestations and diagnosis of menopause. UptoDate, Erișim Adresi: https://www.uptodate.com/contents/clinical-manifestations-and-diagnosis-of-menopause? $\quad$ search= menopause $\% 20$ symptom\%20treatment\&source=search_result\&selectedTitle $=3 \sim 150 \&$

usage_type $=$ default \&display_rank=3\#H313304539.

Cintron, D., Lipford, M., Larrea-Mantilla, L., Spencer-Bonilla, G., Lloyd, R., Gionfriddo, M. R., Murad, M. H. (2017). Efficacy of menopausal hormone therapy on sleep quality: systematic review and meta-analysis. Endocrine, 55(3), 702711. doi:10.1007/s12020-016-1072-9.

Cody, J. D., Jacobs, M. L., Richardson, K., Moehrer, B., \& Hextall, A. (2012). Oestrogen therapy for urinary incontinence in post-menopausal women. The Cochrane Database of Systematic Reviews, 10, CD001405-CD001405. doi:10.1002/14651858.CD001405.pub3.

Cramer, H., Lauche, R., Langhorst, J., \& Dobos, G. (2012). Effectiveness of yoga for menopausal symptoms: a systematic review and meta-analysis of randomized controlled trials. Evid Based Complement Alternat Med, 863905. doi:10.1155/2012/863905.

Daley, A., Stokes-Lampard, H., Thomas, A., \& MacArthur, C. (2014). Exercise for vasomotor menopausal symptoms. Cochrane Database of Systematic Reviews (11). doi:10.1002/14651858.CD006108.pub4.

Dodin, S., Blanchet, C., Marc, I., Ernst, E., Wu, T., Vaillancourt, C., Maunsell, E. (2013). Acupuncture for menopausal hot flushes. Cochrane Database of Systematic Reviews (7). doi:10.1002/14651858.CD007410.pub2.

Faubion, S. S., Larkin, L. C., Stuenkel, C. A., Bachmann, G. A., Chism, L. A., Kagan, R., Kingsberg, S. A. (2018). Management of genitourinary syndrome of menopause in women with or at high risk for breast cancer: consensus recommendations from the north american menopause society and the international society for the study of women's sexual health. Menopause (New York, N.Y.), 25(6), 596-608. doi:10.1097/gme.0000000000001121.

Formoso, G., Perrone, E., Maltoni, S., Balduzzi, S., Wilkinson, J., Basevi, V., et al. (2016). Short-term and long-term effects of tibolone in postmenopausal women. Cochrane Database of Systematic Reviews (10). doi:10.1002/14651858.CD008536.pub3.

Gaudard, A., Silva de Souza, S., Puga, M. E. S., Marjoribanks, J., da Silva, E. M. K., \& Torloni, M. R. (2016). Bioidentical hormones for women with vasomotor symptoms. Cochrane Database of Systematic Reviews (8). doi:10.1002/14651858.CD010407.pub2.

Gönenç, İ., \& Koç, G. (2019). Menopoz dönemine yönelik uygulanan eğitim programının kadınların menopoza yönelik tutumlarına etkisi. SD ̈̈ Să̆llk Bilimleri Dergisi, 10(1), 29-33.

Gün, Ç., \& Demirci, N. (2015). Menopozda bitkisel tedavi kullanımı. Arşiv Kaynak Tarama Dergisi, 24(4), 520-530.

Huang, A. J., Phillips, S., Schembri, M., Vittinghoff, E., \& Grady, D. (2015). Device-guided slow-paced respiration for menopausal hot flushes: a randomized controlled trial. Obstetrics and Gynecology, 125(5), 1130-1138. doi:10.1097/AOG.0000000000000821.

Kagan, R., Kellogg-Spadt, S., \& Parish, S. J. (2019). Practical treatment considerations in the management of genitourinary syndrome of menopause. Drugs \& aging,36(10), 897-908. doi:10.1007/s40266-019-00700-w.

Karakoç, H., Özerdoğan, N., \& Uçtu, A. K. (2017). Menopozla ilgili genitoüriner sendrom. Jinekoloji Obstetrik ve Neonatoloji Tip Dergisi, 14(3), 122-126.

Karanth, L., Chuni, N., \& Nair, N. S. (2019). Antidepressants for menopausal symptoms. Cochrane Database of Systematic Reviews (9). doi:10.1002/14651858.CD013417.

Kazand1, M., \& Akman, L. (2007). Postmenopozal kadınlarda Tibolon'un tolerebilitesi, vajinal kanama oranı ve meme semptomları. Ege Tip Dergisi, 46(3), 141-144.

Kilci, Ş., \& Ertem, G. (2019). Menopozda semptom yönetiminde kullanilan kanita dayali uygulamalar. Sakarya Üniversitesi Holistik Să̆llk Dergisi, 2(3), 36-54.

Lethaby, A., Ayeleke, R. O., \& Roberts, H. (2016). Local oestrogen for vaginal atrophy in postmenopausal women. Cochrane Database of Systematic Reviews (8). doi:10.1002/14651858.CD001500.pub3.

Levin, V. A., Jiang, X., \& Kagan, R. (2018). Estrogen therapy for osteoporosis in the modern era. Osteoporosis International,29(5), 1049-1055. doi:10.1007/s00198-018-4414-Z.

Mitchell, C. M., Reed, S. D., Diem, S., Larson, J. C., Newton, K. M., Ensrud, K. E., Guthrie, K. A. (2018). Efficacy of vaginal estradiol or vaginal moisturizer vs placebo for treating postmenopausal vulvovaginal symptoms: a randomized clinical trial. JAMA Intern Med, 178(5), 681-690. doi:10.1001/jamainternmed.2018.0116.

Monteleone, P., Mascagni, G., Giannini, A., Genazzani, A. R., \& Simoncini, T. (2018). Symptoms of menopause - global prevalence, physiology and implications. Nature reviews. Endocrinology, 14(4), 199-215. doi:10.1038/nrendo.2017.180.

NAMS. (2010). North American Menopause, Society. Estrogen and progestogen use in postmenopausal women: 2010 position statement of The North American Menopause Society. Menopause (New York, N.Y.), 17(2), $242-255$. doi:10.1097/gme.0b013e3181d0f6b9.

NAMS. (2013). Management of symptomatic vulvovaginal atrophy: 2013 position statement of The North American Menopause Society. Menopause (New York, N.Y.), 20(9), 888-904. doi:10.1097/GME.0b013e3182a122c2.

Nelson, H. D., Vesco, K. K., Haney, E., Fu, R., Nedrow, A., Miller, J., Humphrey, L. (2006). Nonhormonal therapies for menopausal hot flashes: systematic review and meta-analysis. JAMA, 295(17), $2057-2071$. doi:10.1001/jama.295.17.2057.

NICE. (2015). Menopause. NICE guideline NG23, recommendation 1.2.1. Erişim Adresi: https://www.nice.org.uk/guidance/ng23/chapter/Recommendations. 
Özcan, H., \& Oskay, Ü. (2013). Menopoz döneminde semptom yönetiminde kanıta dayalı uygulamalar. Göztepe Tip Dergisi, 28(4), 157-163.

Radominski, S. C., Bernardo, W., Paula, A. P. d., Albergaria, B.-H., Moreira, C., Fernandes, C. E., Borba, V. Z. C. (2017). Brazilian guidelines for the diagnosis and treatment of postmenopausal osteoporosis. Revista Brasileira de Reumatologia, 57 Suppl 2, 452-466. doi:10.1016/j.rbre.2017.07.001.

Roberts, H., \& Hickey, M. (2016). Managing the menopause: An update. Maturitas, 86, 53-58. doi:10.1016/j.maturitas.2016.01.007.

Rosen, N. H. M., \& Drezner, M. K. (2020). Overview of the management of osteoporosis in postmenopausal women. UptoDate, Erişim Adresi: https://www.uptodate.com/contents/overview-of-the-management-of-osteoporosis-inpostmenopausal-women?search=menopause $\% 20$ symptom $\% 20$ treatment $\&$ topicRef $=7395 \&$ source=related_link.

Saensak, S., Vutyavanich, T., Somboonporn, W., \& Srisurapanont, M. (2013). Effectiveness of a modified version of the applied relaxation technique in treatment of perimenopausal and postmenopausal symptoms. International Journal of Women's Health, 5, 765-771. doi:10.2147/IJWH.S53652.

Saensak, S., Vutyavanich, T., Somboonporn, W., \& Srisurapanont, M. (2014). Relaxation for perimenopausal and postmenopausal symptoms. Cochrane Database of Systematic Reviews(7). doi:10.1002/14651858.CD008582.pub2.

Salehi-Pourmehr, H., Ostadrahimi, A., Ebrahimpour-Mirzarezaei, M., \& Farshbaf-Khalili, A. (2020). Does aromatherapy with lavender affect physical and psychological symptoms of menopausal women? A systematic review and metaanalysis. Complement Ther Clin Pract, 39, 101150. doi:10.1016/j.ctcp.2020.101150.

Sangkomkamhang, T., Sangkomkamhang, U. S., \& Ngamjarus, C. (2010). Vitamin K for the prevention and treatment of osteoporosis in post-menopausal women. Cochrane Database of Systematic Reviews (1). doi:10.1002/14651858.CD008329.

Santen, J. R., Loprinzi, L. C., \& Casper, F. R. (2019). Menopausal hot flashes. UptoDate, Erişim Adresi: https://www.uptodate.com/contents/menopausal-hot-flashes?search=menopause $\% 20$ symptom $\% 20$ treatment\&source=search_result \&selectedTitle=1 150\&usage_type=default\&display_rank=1.

Santoro, N., Epperson, C. N., \& Mathews, S. B. (2015). Menopausal symptoms and their management. Endocrinology and Metabolism Clinics of North America, 44(3), 497-515. doi:10.1016/j.ecl.2015.05.001.

Shamliyan, T. A., Kane, R. L., Wyman, J., \& Wilt, T. J. (2008). Systematic review: randomized, controlled trials of nonsurgical treatments for urinary incontinence in women. Annals of Internal Medicine, 148(6), 459-473. doi:10.7326/0003-4819-148-6-200803180-00211.

Shepherd-Banigan, M., Goldstein, K. M., Coeytaux, R. R., McDuffie, J. R., Goode, A. P., Kosinski, A. S., Williams, J. W., Jr. (2017). Improving vasomotor symptoms; psychological symptoms; and health-related quality of life in peri- or postmenopausal women through yoga: An umbrella systematic review and meta-analysis. Complement Ther Med, 34, 156164. doi:10.1016/j.ctim.2017.08.011.

Sindel, D., \& Gula, G. (2015). Osteoporozda kemik mineral yoğunluğunun değerlendirilmesi. Turk J Osteoporos, 21(1), 2329.

Soares, C. N., \& Murray, B. J. (2006). Sleep disorders in women: clinical evidence and treatment strategies. Psychiatr Clin North Am, 29(4), 1095-1113; abstract xi. doi:10.1016/j.psc.2006.09.002.

TEMD. (2019). Osteoporoz ve metabolik kemik hastalıkları tanı ve tedavi kılavuzu. Türkiye Endokrinoloji ve Metabolizma Derneği.

Timur, S., \& Hotun Şahin, N. (2010). Menopoz ve uyku. Maltepe Üniversitesi Hemşirelik Bilim ve Sanatı Dergisi, 3(3), 6167.

Tong, I. L. (2013). Nonpharmacological treatment of postmenopausal symptoms. The Obstetrician \& Gynaecologist, 15(1), 19-25. doi:10.1111/j.1744-4667.2012.00143.x.

Ward, K., \& Deneris, A. (2018). An Update on menopause management. Journal of Midwifery \& Women's Health, 63(2), 168-177. doi:10.1111/jmwh.12737.

Ziaei, S., Kazemnejad, A., \& Zareai, M. (2007). The effect of vitamin E on hot flashes in menopausal women. Gynecol Obstet Invest, 64(4), 204-207. doi:10.1159/000106491. 


\section{EXTENDED ABSTRACT}

Menopause is defined as a condition of permanent cessation of menstrual bleeding after 12 months of amenorrhea. Although it varies among women, it is generally stated that the average age of occurrence is 51. 2-6 years before menopause are called the premenopausal period and 6-8 years after menopause as postmenopausal period. Its basic mechanism depends on the decrease in estrogen level and the increase of following-stimulating hormone level. Women report many symptoms during menopause. These symptoms cause many physiologic, mental, social and sexual changes in women. The most severe symptoms are seen during premenopause due to the marked fluctuations in sex hormone levels that occur in the follicular and luteal phases of the menstrual cycle. In postmenopause, symptoms such as vasomotor symptoms, urogenital atrophy, aging of the skin, sleep disorders, psychological changes and osteoporosis may occur due to the absence of estrogen. There are various treatment options for these symptoms of menopause that affect the individual's quality of life and functionality. Healthcare professionals should use evidence based practices to provide the most effective and useful treatment for individuals. For this reason, the review was made to examine the treatment methods used in symptom management in the context of clinical evidence. In this review, menopausal symptoms; vasomotor symptoms, sleep disorders, genitourinary syndrome, osteoporosis and psychological problems were examined.

Vasomotor symptoms are menopausal symptoms characterized by a sudden increase in temperature in the upper body, rash, heart palpitations, tremors, and sweating. Although it affects most women during the menopausal period, it may also differ among women in terms of violence, frequency and duration. The basic idea that guides the treatment in vasomotor symptoms is to determine the disturbing symptoms. Before deciding on treatment, women should be informed about behavioral and pharmaceutical treatments and the most appropriate method should be decided. When the studies conducted are examined, it is stated that hormone therapies containing only estrogen or progesterone together with estrogen for vasomotor symptoms are the most effective treatment method individuals without contraindications. Approximately $40-60 \%$ of women in the menopausal period have problems with sleep, and it is stated that night awakenings are the most common of these. Although it is not explained the mechanism by which sleep disturbances, vasomotor symptoms, it is often thought to be caused by changing hormone levels, lifestyle factors, and other medical conditions that are present. It is stated that the approach to treatment in sleep related problems should be done according to clinical findings and should be addressed in related factors that may affect sleep disorder. Genitourinary syndrome describes changes in the labia major / mimor, clitoris, vestibule, vagina, urethra and bladder as a result of the decrease in sex hormones during menopause. Non-hormonal vaginal lubricants are recommended in primary care management of genitourinary syndromes. It is stated that the use of vaginal estrogen is the most effective treatment for women who do not have any contraindications for low to moderate vaginal atrophy when there is no response from non-hormonal treatments. Osteoporosis is a systemic disease characterized by increased bone fragility as a result of determination in bone mass and tissue. It is one of the important health problems seen in the menopausal period and is cited as an important cause of morbidity and mortality. The decrease in estrogen hormone level is shown as the main reason. It is stated that pharmacological treatment should not be considered in premenopausal women unless there is ongoing bone loss or fractures with low trauma. The use of bisphosphonates as first-line therapy in postmenopausal women is recommended with a high level of evidence. In premenopausal and postmenopausal periods, due to fluctuations in estrogen level, the central nervous system is affected and some mental changes may occur. While it is most common for the individual to feel sad, angry, nervous and restless, it can also cause forgetfulness by making concentration difficult. In addition to all these effects, it is stated that, together with the symptoms brought about by the menopause period, women feel old and cause a decrease in self-esteem. For psychological problems, considering the environmental stress factors affecting women, determining the situation causing the distress and providing the necessary support to suitable for structure of women the basic approach point in treatment.

In the menopausal period, which is an important life phase of women, the management of the symptoms that emerge is very important. It is stated that the prevention and treatment of menopausal symptoms can be provided by using evidence based practices. Therefore, the use of evidence based practices by healthcare personnel is extremely important in improving the quality of care and providing effective care. It is of great importance that all health professionals, especially nurses, who spend the most time with the patient, are able to make evidence-based practices, research and transfer them to applications. Training and counseling services, especially by nurses, will provide a great benefit to women in coping with menopausal symptoms.

Conclusion and Suggestions: The use of evidence-based practices for women in the menopause period is of great importance in increasing the quality of care provided. In particular, education and counseling services to be provided by nurses will benefit women in dealing with menopausal symptoms. 